
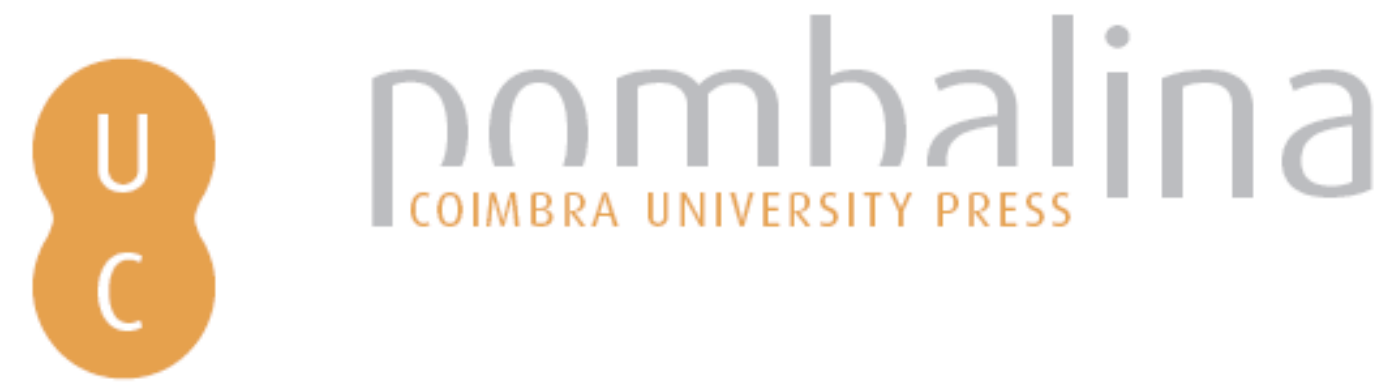

\title{
A gestão de recursos humanos e as percepções, atitudes e bem estar dos trabalhadores: um estudo comparativo de dois casos
}

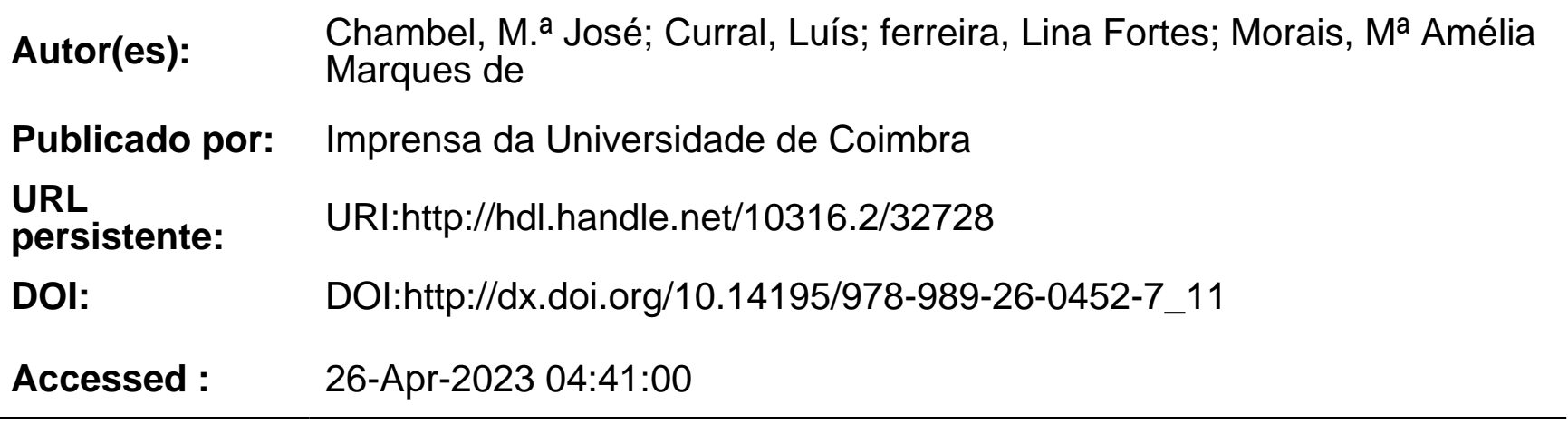

A navegação consulta e descarregamento dos títulos inseridos nas Bibliotecas Digitais UC Digitalis, UC Pombalina e UC Impactum, pressupõem a aceitação plena e sem reservas dos Termos e Condições de Uso destas Bibliotecas Digitais, disponíveis em https://digitalis.uc.pt/pt-pt/termos.

Conforme exposto nos referidos Termos e Condições de Uso, o descarregamento de títulos de acesso restrito requer uma licença válida de autorização devendo o utilizador aceder ao(s) documento(s) a partir de um endereço de IP da instituição detentora da supramencionada licença.

Ao utilizador é apenas permitido o descarregamento para uso pessoal, pelo que o emprego do(s) título(s) descarregado(s) para outro fim, designadamente comercial, carece de autorização do respetivo autor ou editor da obra.

Na medida em que todas as obras da UC Digitalis se encontram protegidas pelo Código do Direito de Autor e Direitos Conexos e demais legislação aplicável, toda a cópia, parcial ou total, deste documento, nos casos em que é legalmente admitida, deverá conter ou fazer-se acompanhar por este aviso.

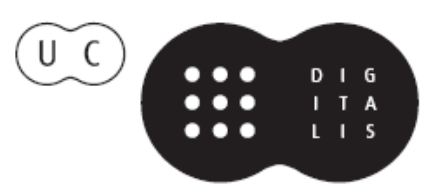




\section{A. DUARTE GOMES - ANTÓNIO CAETANO JOSÉ KEATING • MIGUEL PINA E CUNHA

\author{
Coordenadores
}

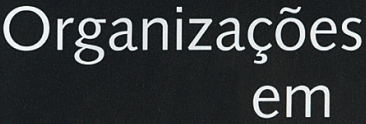

Transição

Contributo da Psicologia do Trabalho

e das Organizaçōes 
(Página deixada propositadamente em branco) 


\section{A. DUARTE GOMES - JOSÉ KEATING ANTÓNIO CAETANO - MIGUEL PINA E CUNHA Coordenadores}

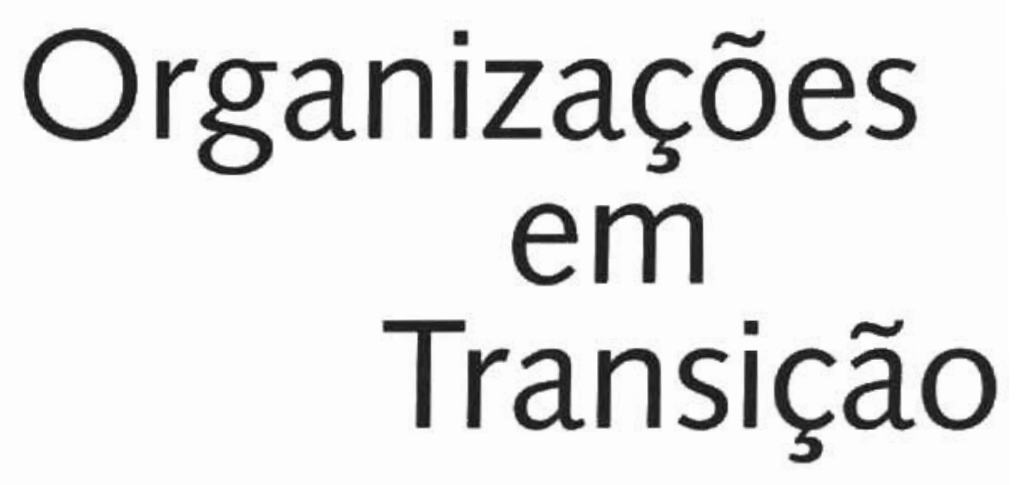

Contributos da Psicologia do Trabalho e das Organizações 


\section{COORDENACÁO EDITORIAL \\ Imprensa da Universidade de Coimbra \\ CONCEPÇÃO GRAFACA \\ António Barros \\ EXECUÇÃO GRAFICA \\ G.C. - Gráfica de Coimbra, Lda. \\ Palheira - Assafarge - Apart. 3068 \\ 3001-453 Coimbra Codex}

ISBN

972-98225-3-0

DEPOSITO LEGAL.

153435/00

(c) JunHo 2000. Imprensa da Universidade de Coimbra 


\title{
A GESTÃO DE RECURSOS HUMANOS E AS PERCEPÇÕES, ATITUDES E BEM ESTAR DOS TRABALHADORES: UM ESTUDO COMPARATIVO DE DOIS CASOS
}

\author{
M.. José Chambel (1), luis Curral (I), \\ lina fortes Ferreira (2) e Ma Amella Marques de Morais (2) \\ (1) FACULDADE DE PSICOLOGIA E DE CIÉNCIAS DA EDUCAÇÃO DA UNIVERSIDADE DE LSBOA \\ (2) ESCOLA SUPERIOR DE CIENCIAS EMPRESARIAIS DO INSTITUTO POUTÉCNICO DE SETÚBAL
}

\section{INTRODUÇÁO}

Diversificada pesquisa tem procurado relacionar determinadas práticas de gestão de recursos humanos com o desempenho organizacional. Algumas delas indicam uma relação positiva entre 0 desempenho da organização e os processos de selecção sofisticados (Becker \& Huselid, 1992), os investimentos em formação (Bartel, 1994), os sistemas de recompensas (Gerhart \& Milkovich, 1992) e os sistemas de participação dos empregados (Wagner III, 1994).

Lado e Wilson (1994) consideraram que a gestão de recursos humanos podia desenvolver um conjunto de práticas que permitiam utilizar as competências organizacionais, contribuindo para um melhor desempenho organizacional. Dentro dessas práticas, os autores referiram a selecção de empregados adequados à organização como um todo, a socialização extensa dos novos empregados, o desenvolvimento de sistemas de avaliação de desempenho, as estratégias de recompensas baseadas nas competências e a formação e o desenvolvimento. Mais ainda, estes autores consideraram que, ter pouco 
em consideração a congruência do empregado e da organização, desenvolver práticas ambivalentes do ponto de vista ético e atribuir aos empregados funções com pouco significado, podiam ser consideradas práticas que destruíam as competências da organização e, consequentemente, levavam a uma diminuição do seu desempenho.

$\mathrm{Na}$ revisão de literatura efectuada por Huselid (1995), este referiu, explicitamente, que determinadas práticas de gestão de recursos humanos aumentavam o desempenho da organização. Este autor considerou que $\circ$ recrutamento extensivo, a selecção, a formação, a partilha formal de informação, a medição de atitudes, o desenho do trabalho, os programas de participação, a avaliação de desempenho e os sistemas de recompensas, as promoçōes e os incentivos que reconheciam e recompensavam o mérito dos empregados, estavam relacionados com resultados positivos no desempenho da empresa (p. 640).

Verifica-se, no entanto, nesta pesquisa que partilha esta ideia de que a gestão de recursos humanos pode contribuir para melhorar os resultados organizacionais, que é difíil estabelecer como deve ser essa gestão. Diferentes estudos incluem diferentes práticas e, por vezes, algumas práticas são consideradas por uns autores eficazes, e, por outros, ineficazes (Youndt, Snell, Dean. \& Lepak, 1996, p.840; Becker \& Gerhart, 1996, p.785).

Huselid (1995) refere que esta dificuldade pode resultar do facto da maioria dos estudos se centrar numa prática particular de gestão dos recursos humanos e não observar o sistema total das práticas a este nível. Cada uma das práticas de recursos humanos pode ter pouca influência no desempenho da organização, mas em conjunto com as outras práticas, pode ter uma influência importante nos resultados da organização sobretudo quando existe uma elevada adequação entre si (Becker \& Gerhart, 1996). A configuração do conjunto de práticas de recursos humanos é que provoca uma sinergia positiva, a qual aumenta a vantagem competitiva da organização porque di-

282 minui a possibilidade de imitação por parte dos concorrentes (Lado e Wilson, 1994).

Por outro lado, a maioria dos autores integrados no estudo da gestão de recursos humanos tem salientado o facto da relação entre a gestão de recursos humanos e o desempenho das organizações não ser uma relação directa, mas moderada pelo comportamento e as atitudes dos indivíduos da organização. 
Considera-se que. numa era em que não é só o preço dos produtos que determina a escolha dos clientes e, consequentemente, orienta a estratégia da organização, mas uma série de outros critérios, como a qualidade, os prazos de fornecimento, a variedade e a assistência pós-venda, as pessoas nas organização ganham um novo relevo. Concretamente, refere-se que é necessário que os empregados consigam manter e promover esses critérios, o que implica não só um bom nível de competência técnica, mas um determinado grau de envolvimento com o seu trabalho e a organização de que fazem parte. Como referem, por exemplo. Walton (1985). Lawler (1992) e Cotton (1993), só envolvendo os empregados, uma organização consegue desenvolver produtos menos caros, com maior qualidade e mais inovadores.

Numa revisão exaustiva da literatura, Meyer e Allen (1997) concluíram que o compromisso dos trabalhadores apresentava uma relação positiva com o desejo de permanecer na empresa, com comportamentos extra-papel que são importantes para o sucesso da organização (por exemplo, ajudar os colegas, oferecer-se para realizar tarefas não estipuladas na função e dar sugestões para melhorar o funcionamento), com a satisfação com a carreira e a satisfação geral com a vida e com o desempenho; e uma relação negativa com o absentismo e o stress no trabalho. Segundo os autores, diferentes práticas de gestão dos recursos humanos apresentavam uma relação positiva com esta atitude de compromisso, nomeadamente: o nível de pagamento; a distribuição de recompensas de forma equitativa; o reconhecimento da objectividade da avaliação de desempenho; a existência de promoções e a sua justiça: a formação; a segurança de emprego; a utilização de informação realista no recrutamento, salientando os aspectos positivos e os negativos da organização e do trabalho; as estratégias de socialização que reforçavam as características dos indivíduos; a posse de acçōes da organização por parte dos trabaIhadores; a existência de benefícios ligados aos cuidados à familia.

Arthur (1994) desenvolveu um estudo empírico no sentido de avaliar - impacto de um determinado sistema de recursos humanos. Com este estudo, o autor ultrapassou a limitação de procurar a influência de apenas uma prática de gestão de recursos humanos, porque considerou o conjunto das práticas de gestão de recursos humanos como um cluster, isto é, um conjunto de objectivos e respectivas práticas que são complementares ou sinérgicas entre si. Neste estudo o autor encontrou um sistema de gestão de recursos humanos que apelidou de controlo e outro a que chamou de 
compromisso. O objectivo do sistema de controlo dos recursos humanos era reduzir os custos directos do trabalho, ou aumentar a eficiência, obrigando os empregados a seguir determinadas regras e procedimentos e baseando as recompensas dos empregados nos resultados (Eisenhardt; Walton, cit. in Arthur, 1994, p. 672.). O sistema de compromisso procurava criar uma ligação psicológica entre os objectivos organizacionais e os empregados.

Este autor considerou que estes diferentes objectivos em relação aos recursos humanos levavam a diferentes práticas. $O$ sistema de controlo obrigava ao desenvolvimento de padrões e à medição precisa dos resultados de cada empregado, sendo as recompensas atribuídas com base nessas avaliaçōes. Pelo contrário, num sistema de compromisso desenvolviam-se os mecanismos precisos de seleç̧ão, de participação na decisão, o treino dos grupos na resolução de problemas e as actividades de socialização, tendo em vista a permanência dos indivíduos na organização e a adesão aos seus objectivos.

Este autor verificou que o tipo de sistema de recursos humanos adoptado pela organização tinha impacto diferente nas atitudes dos trabalhadores e, consequentemente, apresentavam repercussōes também distintas, tanto no desempenho, como no turnover dos seus membros.

Num estudo mais extenso, que incluiu uma amostra nacional com perto de 1000 empresas de diferentes indústrias, Huselid (1995) estudou também o impacto de diferentes práticas de gestão de recursos humanos. Tal como o autor anterior, considerou que as práticas da gestão de recursos humanos deviam ser avaliadas como um todo e distinguiu como um sistema eficaz de gestão de recursos humanos aquele que apelidou de próticas de trabalho de elevado desempenho. Neste sistema distinguiu dois grandes grupos. No primeiro, incluiu o conjunto de práticas destinadas a melhorar as competências dos empregados e as estruturas que lhes permitiam usar essas competências na realização do seu trabalho, nomeadamente, os esforços intensivos de recrutamento, os mecanismos de selecção, o desenho do trabalho, os meca-

284 nismos de participação, o número médio de horas de formação por empregado, os procedimentos de greve, os planos de partilha de informação e os sistemas de partilha dos lucros da empresa.

No segundo grupo, incluiu as práticas destinadas a reconhecer e reforçar os comportamentos desejados dos empregados, isto é, os comportamentos destinados a promover o seu envolvimento. Especificamente, referiu os mecanismos formais de avaliação de desempenho, a ligação destes 
mecanismos aos sistemas de recompensas e aos mecanismos de promoção baseados no mérito.

Verificou que estes dois grupos de práticas de gestão dos recursos humanos tinham impactos distintos no comportamento e nas atitudes dos trabalhadores e, consequentemente, nos resultados das organizaçōes.

Em todas estas investigações, aparece como dificuldade a tentativa de definir qual o sistema de gestão de recursos humanos ou, mais especificamente, quais as práticas de recursos humanos capazes de promover as atitudes positivas por parte dos trabalhadores. Tal como referimos anteriormente, em relação ao desempenho, cada autor estabelece, também, em relação às atitudes, um sistema ou um conjunto de práticas diferentes.

Esta dificuldade, por um lado, mostra a necessidade de continuar a desenvolver pesquisa que identifique a relação entre o conjunto de práticas de gestão de recursos com diferentes atitudes por parte dos trabalhadores. Por outro lado, incentiva a procura de diferentes variáveis que possam mediar a relação entre estas duas variáveis.

Schneider, Brief e Guzzo (1996) referiram o clima organizacional como uma dessas variáveis mediadoras. Segundo estes autores, apesar das organizações implementarem novas práticas de recursos humanos tendo em vista o aumento do seu desempenho, esta influência depende do efeito que essas mesmas práticas tiverem, em primeiro lugar, no clima organizacional e, em segundo lugar, nas atitudes dos indivíduos.

O clima organizacional, o qual constitui uma variável tradicional na psicologia social das organizações, tem sido, desde o início, associado às atitudes dos indivíduos no contexto do seu trabalho. Considera-se hoje, o clima organizacional como a percepção que os empregados têm das políticas, práticas e procedimentos organizacionais e que podem ser formais ou informais. Podemos considerar que este conceito opera a diferentes níveis: psicológico, que se refere ao conjunto de percepções de um membro da organização; grupal, que se refere ao conjunto de percepçōes partilhadas pelos elementos desse grupo; organizacional, que se refere ao conjunto de percepções partilhadas por todos os membros da organização.

Por outro lado, muitos estudos têm mostrado que as características do trabalho têm influência nas atitudes face ao trabalho (Hackman \& Oldham, 1980; Wall \& Martin, 1994). Se considerarmos que determinadas práticas de gestão de recursos humanos (por exemplo, os programas de enriquecimento 
do trabalho, a criação de grupos semi-autónomos, os mecanismos de sugestões) influenciam estas características do trabalho, somos levados a considerálas como uma variável mediadora na relação entre a gestão de recursos humanos e as atitudes face ao trabalho.

No que diz respeito ao bem estar, embora não haja estudos que relacionem directamente práticas de recursos humanos e bem-estar, existem vários estudos que mostram que certas características do trabalho como a exigência qualitativa e quantitativa, a falta de autonomia e a ambiguidade do papel têm efeitos negativos na saúde dos trabalhadores (Cooper \& Payne, 1988). Do mesmo modo, outras dimensões organizacionais como o suporte social e a qualidade das relações entre trabalhadores têm uma relação positiva com - bem-estar dos mesmos (Cropanzano, Howes, Grandey \& Toth, 1997). Assim, podemos esperar que se as práticas de recursos humanos têm influência na percepção das características do trabalho e no clima da organização, então elas possam indirectamente afectar o bem-estar dos trabalhadores.

Nesta investigação procurámos categorizar o sistema de gestão de recursos humanos de duas empresas e observar a sua relação com a percepção que os trabalhadores têm de algumas características do seu trabalho e da sua organização, com algumas das suas atitudes em relação ao trabalho e à organização e com bem estar geral.

\section{MÉTODO}

\subsection{AMOSTRA}

Neste estudo é feita uma comparação entre duas organizações industriais com instalações em Portugal, na mesma região geográfica. Uma das organizações é uma fábrica da indústria electrónica (empresa A), com 427

286 trabalhadores, pertencente a um grupo multinacional. Desta empresa participaram no nosso estudo 255 trabalhadores da área fabril, o que corresponde a $65 \%$ do total de trabalhadores nesta área $(n=390)$. A outra organização é uma fábrica da indústria papeleira (empresa B), com 567 trabalhadores, pertencente a um grupo português. Desta empresa participaram 144 trabaIhadores da área fabril, o que corresponde a $35 \%$ do total de trabalhadores nesta área $(n=419)$. 


\subsection{PROCEDIMENTO}

Foram contactados os Directores de Recursos Humanos de ambas as empresas para aferir do interesse e disponibilidade das mesmas para participar no estudo. Após apresentação dos objectivos e metodologia do estudo. foi combinada a melhor forma de recolher a informação junto dos empregados. Assim, foi acordado fazer reuniōes com as chefias directas e os representantes dos trabalhadores onde foram apresentados os objectivos do estudo e a quem foi pedida ajuda no esclarecimento dos restantes participantes. Uma vez efectuadas estas reuniões, e após acordo em participarem, os questionários foram distribuídos pelos investigadores, no local de trabalho, a todos os indivíduos que trabalhavam na área fabril. A distribuição dos questionários foi feita em vários dias para abranger todos os turnos. Os questionários foram recolhidos pessoalmente pelos investigadores, alguns no próprio dia e os restantes nos dias seguintes. Por fim, ficou combinado que os resultados do estudo respeitantes a cada uma das empresas seriam apresentados aos respectivos participantes.

Na primeira reunião com os Directores de Recursos Humanos, foi ainda agendada uma entrevista com cada um deles para recolher informação sobre as estratégias de recursos humanos postas em prática por cada uma das empresas. Foi igualmente pedido acesso a documentos das empresas que pudessem complementar a informação obtida nas entrevistas.

\subsection{MEDIDAS}

A informação sobre as práticas de recursos humanos utilizadas pelas duas empresas, foi recolhida por meio de entrevistas semi-estruturadas aos respectivos directores de recursos humanos.

As entrevistas foram baseadas num guião onde se exploraram as seguintes práticas de gestão de recursos humanos: recrutamento, selecção, recompensas, carreiras, formação, avaliação de desempenho, sistemas de trabalho e sistemas de informação. Para cada um destes tópicos foram colocadas questões sobre quem era responsável pela implementação das práticas, como se fazia a mesma, desde quando existiam essas práticas, que mudanças estavam projectadas ou pensadas e nos casos em que já existiam mudanças, como 
tinham sido realizadas e aceites pelos empregados. A informação foi depois sintetizada e foram analisadas as práticas vigentes em cada uma das empresas.

A informação sobre características do trabalho, clima da organização, atitudes face ao trabalho e bem-estar dos trabalhadores foi recolhida através de um questionário.

Características do trabalho. São medidas por uma escala composta pelos seguintes factores: Trabalho em equipa ( 4 items, $\alpha=.80$ ). Exigência qualitativa e quantitativa do trabalho ( 5 ítems, $\alpha=.63$ ). Complexidade ( 4 items, $\alpha=.62$ ), Autonomia ( 3 items, $\alpha=.62$ ), Monotonia ( 3 ítems, $\alpha=.71$ ). Os sujeitos registam a sua percepção sobre estas dimensões numa escala de cinco pontos que varia entre Discordo ( 1 ) e Concordo (5).

Clima organizacional. É medido por uma escala composta pelos seguintes factores: Apoio do chefe ( 4 items, $\alpha=.88$ ), Reconhecimento ( 4 tems, $\alpha=.65$ ), Justiça das recompensas ( 4 ítems, $\alpha=.74$ ), Imagem (3 ítems, $\alpha=.74$ ), Relaçães com colegas ( 6 ítems, $\alpha=.72$ ). Os sujeitos registam a sua percepção sobre estas dimensões numa escala de cinco pontos que varia entre Discordo ( I) e Concordo (5).

Atitudes foce ao trabalho. São medidas por uma escala composta pelos seguintes factores: Intenção de saída ( 3 items, $\alpha=.74$ ), Satisfação com as recompensas ( 6 items, $\alpha=.84$ ). Satisfação com as relações entre colegas (4 ítems, $\alpha=.82$ ), Satisfação com a supervisão (3 items, $\alpha={ }^{8}$ ). Satisfação com o trabalho ( 3 ítems, $\alpha=.74$ ). Os sujeitos registam a sua percepção sobre estas dimensões numa escala de cinco pontos que varia entre Discordo ( 1 ) e Concordo (5).

Bem-estor. É um indicador composto por cinco escalas que incluem medidas de saúde física e mental dos trabalhadores. Sintomas psicossomáticos que são avaliados pelo General Health Questionnaire- 12 (Goldberg. 1972), $(\alpha=.82)$; os sujeitos registam a sua percepção numa escala de quatro pontos que varia entre Melhor do que o costume ( 1 ) e Muito pior do que 0

288 costume (4). Saúde geral é medida por 2 ítems, cujas respostas são dadas numa escala de cinco pontos que varia entre Excelente ( 1 ) e Fraca (5). Nível de energia percebido é medido por 6 ítems $(\alpha=.80)$ e as respostas são dadas numa escala de seis pontos que varia entre Todo o tempo ( 1 ) e Nunca (6). Impacto da saúde sobre o trabalho é medido por 7 ítems $(\alpha=.74)$ e as respostas são dadas numa escala dicotómica de $\operatorname{Sim}(1)$ e Não (2):; Depressão é medida pela Depression Scale (Warr. 1971), esta escala tem 6 ítems 
$(\alpha=.86)$ e as respostas são dadas numa escala de seis pontos que varia entre Nunca ( 1 ) e Todo o tempo (6).

\section{RESULTADOS}

A análise das entrevistas realizadas nas duas empresas, revelaram como práticas de gestão de recursos humanos, o seguinte.

Ambas as empresas na sua estratégia de recursos humanos apostam no recrutamento de pessoal qualificado, com elevados níveis de habilitações literárias. Em relação aos técnicos, o nível de habilitação mínimo é o bacharelato e para os operadores $\circ 12^{\circ}$ ano de escolaridade. Relativamente a estes últimos, as duas empresas privilegiam o recrutamento de jovens provenientes das escolas profissionais, ou seja, com formação técnico-profissional, tendo, no entanto, a empresa A baixado o nível de habilitação literária mínimo para $\circ 9^{\circ}$ ano de escolaridade, devido a dificuldades de oferta no mercado de trabalho.

No que diz respeito à selecção de pessoal, enquanto a empresa $A$, apesar de na fase de arranque ter adjudicado esse trabalho a uma empresa externa, - assegura na grande maioria das situações internamente, a empresa B contrata sempre serviços de uma empresa de consultoria especializada. Têm em comum o facto de considerarem que a decisão final cabe aos responsáveis de área, não sendo, no entanto, as chefias directas envolvidas no processo.

Relativamente ao acolhimento e integração dos novos colaboradores, ambas as empresas revelam preocupação com a formação inicial de socialização e de adaptação ao posto de trabalho.

A avaliação de desempenho na empresa $A$ tem como principal objectivo adequar 0 trabalhador à função e a atribuição de prémios (esta apenas aos operadores), enquanto que na empresa B o sistema de avaliação de desempenho está ainda em fase de desenvolvimento, após uma aplicação que foi mal sucedida, devido à não aceitação por parte dos trabalhadores dos critérios e da metodologia utilizada, e que tinha como objectivo a atribuição de um prémio. $O$ instrumento de avaliação é semelhante nas duas empresas (escalas gráficas) e a periodicidade é quadrimestral na empresa $\mathrm{A}$ e semestral na empresa B.

Em 1998 a formação na empresa A representou 4.7\% da massa salarial, enquanto que na empresa B representou $1.04 \%$. Enquanto a área de forma- 
ção na empresa $A$ está integrada no departamento de recursos humanos, na empresa $\mathrm{B}$ a formação é assegurada por um departamento autónomo, denominado centro de formação, sob o pelouro da administração e do qual faz parte o director de recursos humanos, o director de marketing e o director de produção. $\mathrm{Na}$ empresa $\mathrm{A}$ a formação incide em três áreas: área técnica, que representa a maior percentagem de formação ministrada; área comportamental e área de gestão. Na empresa B a formação pode subdividir-se em dois grandes grupos de acordo com a sua natureza e objectivos: formação de desenvolvimento (voluntária), que tem como objectivo principal facilitar a socialização do trabalhador, tendo consequências ao nível da promoção e progressão na carreira, bem como na atribuição de prémios; e formação técnica, orientada para a adaptação ao posto de trabalho, visando essencialmente a qualificação para trabalhar com as novas tecnologias que a empresa tem vindo a introduzir; para além desta, a empresa ultimamente tem apostado na formação das chefias. Relativamente ao processo de análise das necessidades de formação, em ambas as empresas, este é realizado pelos responsáveis de área, que indicam o trabalhador e o tipo de formação que necessita, sendo o plano anual de formação elaborado posteriormente pelo departamento de recursos humanos na empresa $\mathrm{A}$ e pelo departamento de formação autónomo na empresa $B$.

A evolução na carreira na empresa B faz-se por progressão e por promoção, tendo por base critérios de avaliação de desempenho e a frequência das acções de formação promovidas pela empresa. Na empresa A existem apenas dois níveis na função operador, sendo a progressão automática por antiguidade; já no que diz respeito às promoções, o critério é a avaliação de desempenho.

No que diz respeito às recompensas atribuídas, ambas as empresas praticam vencimentos acima do contrato colectivo de trabalho para o sector. Relativamente à política de atribuição de prémios, a empresa $\mathrm{A}$ tem um prémio

290 mensal, apenas para os operadores, calculado com base na avaliação de desempenho e na assiduidade, enquanto que a empresa $B$ tem um prémio de produção mensal para todos os trabalhadores, excepto chefias, e um prémio anual em função dos resultados globais da empresa, constituindo a assiduidade, a disciplina e a colaboração também regras de acesso a estes prémios. As duas empresas têm como regalias sociais, a atribuição de um seguro de saúde e de um seguro de vida a todos os trabalhadores, ao que acresce um 
fundo de pensões na empresa $B$, justificado pelo facto de se tratar de uma empresa mais antiga. Para além destes incentivos extra, a empresa $B$ atribui um subsídio de transporte aos seus trabalhadores, disponibiliza $48 \mathrm{~h}$ anuais para tratar de assuntos vários, que caso não sejam utilizadas são bonificadas trimestralmente e coloca à disposição dos trabalhadores a possibilidade de aquisição de acções a metade do valor de mercado, sendo o seu acesso feito em função do nível de vencimento, ao que acresce a atribuição de diuturnidades em função da antiguidade na empresa. $A$ atribuição de viatura constitui igualmente outra regalia, na empresa $A$, para determinados quadros, com funções de responsabilidade de área e, na empresa $\mathrm{B}$, para todos os responsáveis de área, para além de algumas chefias e trabalhadores com funções comerciais, que têm automóvel atribuído por conveniência de serviço.

No que diz respeito aos programas de participação e envolvimento, apenas a empresa $A$ apresenta um conjunto de programas formais de participação, de que são exemplo o programa de sugestões, os grupos de resolução de problemas e os prémios de excelência e reconhecimento geral. No entanto, convém referir que na empresa $B$ apesar de existir uma caixa de sugestões, não existe nenhum programa formal e estruturado que incentive a participação.

O programa de sugestões é extensivo a todos os trabalhadores da empresa A e incentiva a participação individual e em grupo, sendo todas as sugestões premiadas com um prémio simbólico. Às sugestões aprovadas e concretizadas acresce um prémio pecuniário. Note-se que, a todas as sugestões recebidas é atribuída uma cotação, tendo em conta a relação entre a sugestão apresentada (originalidade, aplicabilidade e natureza) e a função desempenhada pelo proponente individual ou grupal.

Os grupos de resolução de problemas (círculos de qualidade) são constituídos no início de cada ano e compostos por 6 elementos que se reúnem meia hora por semana para discutir e resolver problemas que diagnosticam na empresa, com vista a uma melhoria continua. $O$ grupo que no final do ano apresentar a melhor solução, representa a empresa no festival anual da multinacional.

Outro tipo de programa de participação e envolvimento são os prémios de excelência e de reconhecimento geral, consistindo o primeiro na nomeação do melhor trabalhador do ano pelo corpo de gestão da empresa e o segundo na nomeação do melhor colega pelos pares. Os dois prémios referi- 
dos são de natureza variada, podendo traduzir-se em viagens, produtos da empresa, entre outros.

Relativamente aos sistemas de informação e de comunicação interna, ambas as empresas possuem intranet, através da qual é divulgada a todos os trabalhadores informação sobre a empresa (missão, objectivos e valores da empresa, resultados mensais, etc). As duas organizações possuem um jornal de empresa, distinguindo-se, contudo, nos objectivos e na concepção. $\mathrm{Na}$ empresa A, o jornal tem como objectivo principal a divulgação dos acontecimentos sociais da empresa, privilegiando, por isso, noticias que divulguem o empenho e a iniciativa dos trabalhadores. $\mathrm{Na}$ empresa $\mathrm{B}$, o jornal tem como objectivo principal informar sobre a situação da empresa e da envolvente. Esta diferença de objectivos está patente na própria concepção do jornal: na empresa A a concepção do jornal está dependente das contribuições de todas as áreas funcionais, ficando a sua coordenação a cargo do departamento de recursos humanos; na empresa $\mathrm{B}$ a concepção do jornal é da inteira responsabilidade do departamento de comunicação.

Neste momento as empresas encontram-se numa fase de redução de pessoal, embora por motivos distintos: a empresa A, em virtude do volume de trabalho, uma vez que faz produção por encomenda e a empresa $B$ devido à progressiva automatização do seu processo de produção. $O$ processo de separação tem sido também conduzido de forma diferente: na empresa A, estando a maioria dos trabalhadores contratada a termo, a separação é feita através da caducidade do contrato de trabalho; na empresa $\mathrm{B}$, a redução de pessoal abrange uma população com maior antiguidade e níveis de habilitação literária mais baixos, isto é, uma população efectiva, pelo que o processo de separação envolve a negociação entre a empresa e os delegados sindicais e o próprio trabalhador.

No que diz respeito à percepção dos trabalhadores sobre as características do trabalho, o clima, as atitudes e o bem-estar, foram calculadas as médias

292 e desvios-padrão de todas as dimensões, separadamente para cada empresa.

Na empresa A os trabalhadores têm, em média, uma percepção neutra sobre as exigências e o grau de monotonia do seu trabalho. Esta neutralidade advém do facto de existirem trabalhadores com percepções contrárias sobre estas dimensões (desvios-padrão de .86 e 1.0 , respectivamente). No que diz respeito ao trabalho em equipa e à complexidade, os trabalhadores consideram que estas são características ligeiramente presentes no seu trabalho. Sali- 


\begin{tabular}{|c|c|c|c|c|c|c|c|c|}
\hline & $\begin{array}{l}\text { Trabalho } \\
\text { em equipa }\end{array}$ & Exigência & Complexidade & Autonomia & Monotonia & $\begin{array}{l}\text { Apoio } \\
\text { do chefe }\end{array}$ & Recompensas & Justiça \\
\hline Média & 3.2 & 3.1 & 3.2 & 2.1 & 3.1 & 4.6 & 3.6 & 3.9 \\
\hline \multirow[t]{2}{*}{ D.P. } & 1.3 & .86 & 1.0 & .94 & 1.0 & .61 & .88 & .81 \\
\hline & Imagem & Relaçōes & $\begin{array}{l}\text { Intençāo } \\
\text { de saida }\end{array}$ & $\begin{array}{l}\text { Satusfação } \\
\text { recompensa }\end{array}$ & $\begin{array}{l}\text { Satisfaçāo } \\
\text { relaçōes }\end{array}$ & $\begin{array}{l}\text { Satisfaçāo } \\
\text { supervisão }\end{array}$ & $\begin{array}{l}\text { Satisfaçāo } \\
\text { trabalho }\end{array}$ & \\
\hline Média & 3.6 & 3.1 & 3.1 & 27 & 4.4 & 3.4 & 4.1 & \\
\hline \multirow[t]{2}{*}{ D.P. } & 1.0 & .84 & 1.1 & 1.1 & .69 & 1.2 & .93 & \\
\hline & Sintomas & Saude geral & Energia & Impacto & Depressão & & & \\
\hline Média & 1.9 & 2.9 & 4.6 & 128 & 2.1 & & & \\
\hline D.P. & .31 & .65 & $\pi$ & 1.6 & .79 & & & \\
\hline
\end{tabular}

TABELA I - Médias e desvios-padrão referentes a características do trabalho, clima, atitudes e bem-estar dos trabalhadores da empresa $\mathrm{A}$

entamos que os desvios-padrão destas dimensões ( 1.3 e 1.0 respectivamente) sugerem a existência de percepções opostas. Os participantes percepcionam falta de autonomia para a realização do seu trabalho, nomeadamente a possibilidade de tomar decisões.

No que diz respeito ao clima, os trabalhadores da empresa $A$ consideram que têm um apoio elevado do seu chefe directo, que as recompensas são adequadas ao desempenho e que a sua distribuição é realizada de uma forma equitativa. Esta empresa é ainda percebida como tendo uma imagem de prestígio. A qualidade das relações entre os colegas é percebida de forma neutra, embora o desvio-padrão obtido (.84) nos sugira que existem tantos trabalhadores com uma percepção favorável como aqueles que têm uma percepção desfavorável.

Em relação às atitudes, os trabalhadores da empresa $A$ manifestam uma ligeira insatisfação com as recompensas, uma elevada satisfação com as relaçōes entre colegas, assim como com o seu trabalho. Os participantes mostram alguma satisfação com a sua chefia directa. Quanto à intenção de saída da empresa, esta apresenta um valor neutro, embora o desvio-padrão (I.I) sugira a existência de tantos trabalhadores que manifestam vontade de sair como aqueles que, pelo contrário, não pensam em sair.

No que diz respeito ao bem-estar, os trabalhadores da empresa $A$ não apresentam, em média, sintomas psicossomáticos, dizem ter uma saúde geral boa, sentem-se com níveis de energia apropriada à sua actividade, não consi- 
deram que a sua saúde tenha tido impacto negativo sobre a sua capacidade para realizar o trabalho e raramente apresentam sintomas de depressão.

\begin{tabular}{|c|c|c|c|c|c|c|c|c|}
\hline & $\begin{array}{l}\text { Trabalho } \\
\text { em equipa }\end{array}$ & Exigencia & Complexidade & Autonomia & Monotonia & $\begin{array}{l}\text { Apoio } \\
\text { do chefe }\end{array}$ & Recompensas & Justica \\
\hline Média & 25 & 35 & 26 & 25 & 3.7 & 4.5 & 29 & 24 \\
\hline \multirow[t]{2}{*}{ D.P. } & 97 & 80 & 1.1 & 92 & 10 & 62 & .81 & .92 \\
\hline & Imagem & Relaşōes & $\begin{array}{l}\text { Intençăo } \\
\text { de saída }\end{array}$ & $\begin{array}{l}\text { Satusfação } \\
\text { recompensa }\end{array}$ & $\begin{array}{l}\text { Satıśaçāo } \\
\text { relaçōes }\end{array}$ & $\begin{array}{l}\text { Satısfasão } \\
\text { supervisão }\end{array}$ & $\begin{array}{l}\text { Satisfação } \\
\text { trabalho }\end{array}$ & \\
\hline Média & 2.6 & 2.6 & 3.1 & 20 & 4.1 & 3.3 & 4.2 & \\
\hline \multirow[t]{2}{*}{ D.P. } & 11 & 83 & 1.2 & 92 & 78 & 12 & 94 & \\
\hline & Sintomas & Sauide geral & Energia & impacto & Depressāo & & & \\
\hline Média & 25 & 28 & 4.8 & 13.0 & 2.1 & & & \\
\hline$D P$ & .16 & 63 & 67 & 1.5 & .84 & & & \\
\hline
\end{tabular}

TABELA 2 - Médias e desvios-padrão referentes a características do trabalho, clima, atitudes e bem-estar dos trabalhadores da empresa $B$

Na empresa $\mathrm{B}$ os trabalhadores consideram, em média, que o seu trabaIho é bastante exigente e monótono. No que diz respeito ao trabalho em equipa, à complexidade e à autonomia, os trabalhadores desta empresa consideram que estas características não estão presentes no seu trabalho.

No que diz respeito ao clima, os trabalhadores da empresa $B$ consideram que têm um apoio elevado do seu chefe directo. $A$ adequação das recompensas é percepcionada de uma forma neutra, embora o desvio-padrão sugira que existem tantos trabalhadores com uma percepção favorável como aqueles que têm uma percepção desfavorável. $\mathrm{A}$ equidade na distribuição das recompensas, as relações entre colegas e a imagem da empresa são percebidas como desfavoráveis.

294 Em relação às atitudes, os trabalhadores da empresa B manifestam-se, em média, insatisfeitos com as recompensas. Pelo contrário, mostram-se bastante satisfeitos com as relações entre colegas e com o seu trabalho. Os participantes mostram alguma satisfação com a sua chefia directa. Quanto à intenção de saída da empresa, esta apresenta um valor neutro, embora o desvio-padrão (।.0) sugira a existência de tantos trabalhadores que manifestam vontade de sair como aqueles que, pelo contrário, não pensam em sair. 
No que diz respeito ao bem-estar, os trabalhadores da empresa B consideram, em média, que têm tido alguns sintomas psicossomáticos, que nem sempre têm níveis de energia apropriada à sua actividade e raramente apresentam sintomas de depressão. No entanto, consideram que a sua saúde geral é boa e que a mesma não tem tido impacto negativo sobre a sua capacidade para realizar o trabalho.

Em seguida foram feitas análises comparativas (ANOVA) entre as empresas $A$ e $B$ para as dimensões das características do trabalho, do clima, das atitudes e do bem-estar.

\begin{tabular}{|c|c|c|c|c|c|c|c|}
\hline & $\begin{array}{l}\text { Trabalho } \\
\text { em equipa }\end{array}$ & Exogencia & Complexidade & Autonomia & Monotona & $\begin{array}{l}\text { Apoio } \\
\text { do chefe }\end{array}$ & Recompensas \\
\hline Empresa A & 3.2 & 3.1 & 3.2 & 2.1 & 3.1 & 4.6 & 3.6 \\
\hline \multirow[t]{2}{*}{ Empresa B } & 25 & 3.5 & 2.6 & 25 & 3.7 & 4.5 & 2.9 \\
\hline & Imagem & Relaçōes & $\begin{array}{l}\text { Intenção } \\
\text { de saida }\end{array}$ & $\begin{array}{l}\text { Satisfaçăo } \\
\text { recompensa }\end{array}$ & $\begin{array}{l}\text { Satısfação } \\
\text { relaçōes }\end{array}$ & $\begin{array}{l}\text { Satisfaçăo* } \\
\text { supervisāo }\end{array}$ & $\begin{array}{c}\text { Satisfação* } \\
\text { trabalho }\end{array}$ \\
\hline Empresa A & 3.9 & 3.6 & 3.1 & 27 & 4.4 & 1.9 & 4.6 \\
\hline Empresa B & 24 & 26 & 2.6 & 20 & 4.1 & 25 & 48 \\
\hline
\end{tabular}

As diferencas săo todas significativas para $p<01$ excepto nas assnaladas com *

TABELA 3 - Comparação das características de trabalho, clima, atitudes e bem-estar dos trabaIhadores entre as duas empresas

Nesta comparação podemos verificar que existem diferenças significativas entre a empresa $A$ e a empresa $B$ para quase todas as dimensões medidas. Assim, em relação às características do trabalho, a empresa $A$ apresenta valores significativamente superiores aos da empresa $B$ para todas as dimensões, excepto para a autonomia onde aquela empresa tem um valor inferior ao da empresa B. Quanto ao clima, observamos igualmente que a empresa A apresenta valores significativamente superiores aos da empresa B para todas as dimensões. No que diz respeito às atitudes, observaram-se diferenças significativas apenas na satisfação com as recompensas e na satisfação com as relações, tendo a empresa $A$ apresentado valores superiores aos da empresa B em ambas. Quanto ao bem-estar, apenas se observaram diferenças em relação aos sintomas psicossomáticos e ao nível de energia percebido pelos trabalhadores, sendo também os resultados melhores para a empresa $\mathrm{A}$. 


\section{DISCUSSÃO DOS RESULTADOS}

As empresas apresentam práticas de gestão de recursos humanos semeIhantes. No entanto, os resultados obtidos parecem indicar que estas semeIhanças são maiores a nível dos sistemas de controlo do que de compromisso (Arthur, 1994).

Ambas as empresas têm como objectivo a redução dos custos directos do trabalho, quer através da contratação a termo certo ajustada a uma produção por encomenda (empresa A), quer através da progressiva automatização do processo produtivo (empresa B). Verificam-se também semelhanças a nível do estabelecimento de regras e procedimentos e a nível do estabelecimento de padrões de desempenho. Aliás, a avaliação é um factor importante na evolução na carreira e para a determinação de recompensas em ambas as empresas, apesar do sistema de avaliação de desempenho não estar formalizado na empresa $B$, que utiliza actualmente como critérios de avaliação as informações recolhidas junto das chefias e a frequência das acções de formação profissional.

Ao nivel do sistema de compromisso, isto é, o conjunto de práticas de recursos humanos que procuram criar uma ligação psicológica entre os objectivos organizacionais e individuais, as empresas revelam algumas diferenças que podem ser relevantes do ponto de vista do nosso objecto de estudo. As principais diferenças situam-se ao nível dos programas formais de participação e envolvimento dos trabalhadores.

Apesar da socialização e da formação (comportamental e técnica) constituirem prioridades em ambas as empresas, o incentivo da participação dos trabalhadores na vida organizacional é mais saliente na empresa A. Esta preocupação traduz-se em programas formais de participação e envolvimento de que são exemplo os círculos de qualidade e o programa de sugestões, bem como a concepção do jornal de empresa.

296 O sentimento de participação e de envolvimento na vida organizacional parecem influenciar as diferenças encontradas relativamente à percepção das características do trabalho, clima organizacional, atitudes face ao trabalho e bem estar.

Destas diferenças destacam-se as da percepção do trabalho como sendo realizado em equipa por parte dos trabalhadores da empresa $A$, reforçada pela percepção de que se trata de um trabalho ligeiramente complexo, 
que requer um algumas competências variadas, em oposição à percepção de um trabalho mais individual, monótono e de uma exigência acima das suas competências e do tempo disponível, por parte dos trabalhadores da empresa B. Ora, esta diferença de percepção torna-se relevante na medida em que a organização do trabalho (trabalho em linha), bem como as suas exigências (capacidade de utilização de novas tecnologias, vigilância, etc.) são equivalentes nas duas empresas.

A participação e o envolvimento dos trabalhadores parece ser igualmente responsável pelas diferenças ao nível do clima organizacional. A percepção da equidade nas recompensas e da transparência nos processos de promoção, aparece como o factor com maior amplitude de diferença entre as duas empresas. Esta diferença de percepção parece explicar as dificuldades sentidas na implementação de um sistema de avaliação de desempenho, visando, entre outros, a atribuição de um prémio individual na empresa B. Pelo contrário a existência de programas formais de participação e envolvimento. na empresa A poderá ter contribuído para a percepção de uma maior equidade na atribuição das recompensas.

Esta diferença nas práticas de gestão de recursos humanos pode ter influenciado também a percepção sobre a imagem e o prestígio da empresa, dado que a empresa $A$ apresenta valores mais elevados do que a empresa B.

A percepção do reconhecimento das contribuições individuais e do bom relacionamento entre pares são outros factores que parecem corroborar esta hipótese. Estes dados parecem-nos tanto mais interessantes quanto as práticas de recompensas são efectivamente mais elevadas na empresa $B$ do que na empresa $A$.

No que diz respeito às atitudes face ao trabalho, as práticas de participação e envolvimento dos trabalhadores parecem ser igualmente responsáveis pelas diferenças ao nível da satisfação com as recompensas e com as relações com os colegas. Na realidade, a satisfação com as recompensas é maior na empresa $\mathrm{A}$, o que poderá estar relacionado com a percepção de equidade com as recompensas e com a percepção das recompensas. De igual modo, o envolvimento dos trabalhadores, através dos programas formais de participação na empresa A, poderá estar relacionado com a maior satisfação com os colegas nesta empresa.

Quanto ao bem-estar há diferenças significativas em algumas das áreas 
avaliadas. Nota-se uma diferença ao nível dos sintomas psicossomáticos e da percepçāo da energia para realizar o trabalho, que neste caso poderão estar relacionada com as diferentes percepções e atitudes verificadas nas duas empresas. No entanto, outros factores poderão concorrer para esta diferença, entre os quais, as próprias condições físicas do trabalho que observamos serem efectivamente melhores na empresas $A$.

\section{CONCLUSÓES}

Este estudo parece suportar a ideia de que as práticas de gestão de recursos humanos de uma empresa podem influenciar as percepções dos trabalhadores das mesmas sobre as características do seu trabalho, o clima da organização, as atitudes destes face ao trabalho e o seu bem-estar. Concretamente, diferenças nas práticas de envolvimento das empresas parecem estar associadas a diferenças nas atitudes dos trabalhadores, no clima e nas percepção das características do trabalho, bem como em algumas áreas do bemestar dos empregados, em particular a presença de sintomas psicossomáticos.

No entanto, gostaríamos de destaçar algumas limitações deste estudo. Em primeiro lugar, o facto de a nossa amostra de uma das empresas (empresa B) não ser representativa da mesma, pelo facto de corresponder apenas a $35 \%$ do total dos trabalhadores da área fabril. Em segundo lugar, o nosso estudo não permite definir clusters de práticas de gestão de recursos humanos e seus respectivos efeitos nas percepções das características do trabalho e da organização, nas atitudes e no bem-estar geral dos trabalhadores, por ser um estudo que abrangeu apenas duas empresas. Por último, o nosso estudo não permite compreender se a relação entre as práticas gestão de recursos humanos e as percepções dos trabalhadores sobre as características

298 do seu trabalho, o clima organizacional, as atitudes face ao trabalho e o seu bem-estar é uma relação directa ou se estas práticas têm sobretudo um impacto directo nas percepções das características do trabalho e no clima organizacional e estes últimos, por sua vez, vão influenciar as atitudes e o bem-estar dos trabalhadores.

Porém, pensamos que por um lado, este estudo permite levantar hipóteses sobre a influência que a implementação de certas práticas de gestão de 
recursos humanos pode ter na percepção das características do trabalho, no clima organizacional, nas atitudes e no bem-estar dos trabalhadores. Por outro lado, parece apontar para o facto de que esta influência pode ocorrer independentemente do formato que estas dimensões efectivamente assumem na organização.

\section{REFERENCIAS}

ARTHUR, J.B. (1994). Effects of human resource systems on manufacturing performance and turnover. Academy of Management joumal, 37; 670-687.

BARTEL, A.P. (1994). Productivity gains from the implementation of employee trainung programs. Industrial Relations, 33:411-425.

BECKER, B.E.. \& GERHART, B. (1996). The impact of human resource management on onganizational performance: Progress and prospects. Acodemy of Management fournal, 39: 779-801.

BECKER, B.E., \& HUSELID, M.A. (1992). Direct estimates of SDy and the implications for utility analysis. Journal of Applied Psychology, 77: 227-233.

COOPER C.L. \& PAYNE. R. (1988). Cause, coping and consequences of stress. Chichester, UK: Wiley

CROPANZANO, R., HOWES, J.C., GRANDEY, A. \& TOTH, P. (1997). The relationship of organizational politics and support to work behaviors, attitudes and stress. Journal of Organizational Behovior, Vol. 18. 159-180.

COTTON, J.L (1993). Employee Involvement. Methods for improving performance and work attitudes. London: Sage.

GERHART. B.. \& MILKOVICH. G.T. (1992). Employee compensation: Research and practice. In M.D. Dunette \& LM. Hough (Eds.). Handbook of Industrial and Organizational Psychology. vol.3, pp. 481-569. Palo Alto, CA: Consulting Psychologists Press.

HACKMAN. J.R. \& OLDHAM, G.R. (1980). Work Redesign. Reading, MA. Addison-Wesley.

HUSELID, MA. (1995). The impact of human resource management practices on turnover, productivity, and corporate financial performance. Academy of Management Journal. 38: $635-670$.

LAWLER III, E.E.. (1992). The ultumate advantage. Creating the high-involvement onganization. S. Francisco: Jossey-Bass.

LADO, A.A., \& WILSON, M.C. (1994). Human resource systems and sustained competitive advantage: A competency-based perspective. Academy of Manogement Review, 19:699-727.

MEYER, J.P., \& ALLEN, N.J. (1997). Commitment in the Workplace. Theory, research and application. London: Sage.

SCHNEIDER, B., BRIEF, A.P., \& GUZZO, RA. (1996). Creating a climate and culture for sustainable organizational change. Orgonizational Dynamics. 24:7-19.

WAGNER III, J.A. (1994). Participation's effect on performance and satisfaction: A reconsideration of research evidence. Academy of Management Review 19:312.330. 
WALL, T.D., \& MARTIN, R (1994). Job and work design. In C.L Cooper \& I.T.Robertson (Eds.). Key Reviews in Managerial Psychology. Concepts and research for practice, pp. 158-188. New York John Wiley \& Sons.

WALTON, RE (1985). From control to commitment. Harvard Business Review, 63: 77-84.

YOUNDT, M.A., SNELL. S.A. DEAN, J.W.. \& LEPAK, D.P. (1996). Hurnan resource management, manufacturing strategy, and firm performance. Academy of Manogement Journal, 39: 836-866. 
(Página deixada propositadamente em branco) 
Série

Investigação

Coimbra

Imprensa da Universidade

2000 